\title{
Pelatihan Diversifikasi Produk nntuk Peningkatan Produktivitas Pelaku UKM Tahu
}

\section{Product Diversification Training for Increasing Productivity of Tofu SME Entrepreneur}

\author{
${ }^{1 *}$ Fitrah Sari Islami, ${ }^{2)}$ Rian Destiningsih, ${ }^{3)}$ Andhatu Achsa \\ ${ }^{1,2,3)}$ Program Studi Ekonomi Pembangunan, Fakultas Ekonomi \\ Universitas Tidar \\ Jl. Kapten Suparman No. 39, Magelang \\ *email: fitrahsari@untidar.ac.id
}

DOI:

\begin{abstract}
ABSTRAK dari sisi penjualan. Hal ini disebabkan oleh lemahnya pemasaran produk dan kurangnya inovasi dalam produk usaha. Pengabdian dilakukan dengan tujuan untuk meningkatkan kemampuan mitra dalam melakukan diversifikasi, inovasi dan pemasaran produk untuk peningkatan produktivitas mitra. Mitra dalam kegiatan pengabdian ini adalah para pelaku UKM Tahu yang terdiri dari 20 pengusahan UKM Tahu. Pengabdian dilaksanakan dengan menggunakan metode ceramah, tutorial pembuatan diversifikasi produk dan kegiatan diskusi. Hasil kegiatan pengabdian menunjukkan peningkatan pemahaman pelaku usaha dalam berbagai variasi produk, peningkatan kemampuan pelaku usaha dalam membuat ragam variasi produk salah satunya "tahu walik" dan pengetahuan mengenai strategi dalam pemasaran produk saat ini. Dari pelaksanaan kegiatan ini, para pelaku UKM Tahu tertarik untuk membuat tahu walik. Melalui pelaksanaan kegiatan pengabdian ini, diharapkan dapat meningkatkan kesejahteraan usaha para pelaku UKM Tahu.
\end{abstract}

10.30595/jppm.v5i1.8591 Latar belakang kegiatan pengabdian adalah menurunnya kesejahteraan mitra

Histori Artikel:

Diajukan:

$17 / 09 / 2020$

Diterima:

$10 / 01 / 2022$

Diterbitkan:

$17 / 02 / 2022$

Kata kunci: Diversifikasi Produk; Inovasi; Pemasaran Produk

\begin{abstract}
The background of the program is a decrease in sales and partner welfare. This is due to weak product marketing and a lack of innovation in business products. The program aims to improve partners' ability to diversify, innovate and product marketing to increase partner productivity. Partners in this program are tofu SME entrepreneurs which consist of 20 tofu SME entrepreneurs. The program is implemented using the lecture method, tutorials for making product diversification and discussion activities. The results shows tha program can increase the understanding of tofu SME entrepreneurs in variations product, increase the ability of tofu SME entrepreneurs to make variations product such as "tahu walik" and knowledge of current product marketing strategies. From this program, tofu SME entrepreneurs interested to make "tahu walik" product and hopefully, it can improve the business welfare of tofu SME entrepreneurs.
\end{abstract}

Keywords: Product Diversification; Innovation; Product Marketing

\section{PENDAHULUAN}

Pertumbuhan UKM telah diakui sebagai salah satu pendongkrak perekonomian Indonesia. Peran terbesar yang dilakukan UKM bagi perekonomian yaitu tingginya penyerapan tenaga kerja dari sektor UKM. Sehingga hal ini dapat memicu peningkatan kesejahteraan, bukan saja kesejahteraan tenaga kerja UKM, tetapi juga kesejahteraan pelaku UKM tersebut. Hal ini menjadi penyebab 
betapa pentingnya kegiatan pengembangan UKM untuk diutamakan sebagai kegiatan pengabdian di bidang ekonomi.

Salah satu bidang UKM yang telah mengalami permasalahan yaitu UKM tahu di Kampung Trunan, Kota Magelang. Bisnis yang berada di bawah naungan Primer Koperasi Produsen Tempe Tahu Indonesia (PRIMKOPTI) ini tengah menghadapi penurunan produktivitas sebagai akibat dari berkurangnya pendapatan UKM tahu tersebut.

Sebelumnya di era 90an, UKM tahu Kampung Trunan mengalami kejayaan dan berhasil meningkatkan skala usaha. Keberhasilan ini juga didukung oleh PRIMKOPTI sebagai saluran dana dalam bentuk kredit demi memudahkan UKM tahu dalam memperbesar usaha. Namun, akibat dari turunnya skala penjualan pada beberapa tahun terakhir ini, menyebabkan kondisi produsen tahu tersebut semakin meredup. Terlebih eksistensi PRIMKOPTI yang memiliki keterikatan dengan para pelaku UKM tahu juga menjadi redup. Hal ini menjadi penyebab sulitnya UKM tahu bangkit dari kondisi saat ini.

Tantangan UKM tahu saat ini yaitu banyaknya produk makanan lain yang jauh lebih bervariasi, sehingga menyebabkan penurunan minat masyarakat dalam mengkonsumsi tahu. Selain itu, penurunan pangsa pasar tahu ini juga disebabkan karena masyarakat kurang mengenal kebaharuan dari produk tahu. Sehingga pengabdian ini mengarahkan kepada diversifikasi, inovasi serta pemasaran produk dalam meningkatkan produktivitas usaha UKM tahu di Kampung Trunan, Kota Magelang.

Salah satu cara yang dapat dilakukan dalam menaggapi masalah tersebut yaitu dengan melakukan diversifikasi produk. Diversifikasi biasa dilakukan UKM untuk peningkatan pendapatan usaha (Murphy \& Tocher, 2017). Selain itu, strategi diversifikasi produk dapat menambah nilai ekonomis produk sehingga dapat meningkatkan pendapatan masyarakat (Anggraini et al., 2019). Dalam kegiatan pengabdian yang dilakukan oleh Elita et al., (2018) dan pengabdian Khairani \& Pratiwi (2018) menyatakan bahwa diversifikasi produk telah meningkatkan omset penjualan.

Selain diversifikasi produk, inovasi Inovasi produk juga merupakan cara yang dapat diupayakan oleh UKM tahu. Inovasi merupakan bagian yang sangat penting bagi keberhasilan perusahaan dan kelangsungan hidup UKM dalam jangka panjang (Brines et al., 2013). Hasil penelitian sebelumnya menyatakan bahwa inovasi memberikan pengaruh terhadap kinerja UKM (Saunila, 2019). Kinerja tersebut berupa hasil pendapatan usaha sesuai target penghasilan UKM. Dalam kegiatan pengabdian yang dilakukan oleh Marka et al., (2019) menyatakan bahwa inovasi produk dapat memberikan tambahan pengetahuan dan keterampilan pelaku usaha. Sewajarnya, budaya inovasi memang harus dimiliki dan ditanamkan dalam diri pelaku usaha (Haddad et al., 2019). Karena, hal ini akan memberikan kemampuan untuk menggali ide-ide baru dalam inovasi produk.

Faktor penting lainnya dalam peningkatan produktivitas usaha yaitu pemasaran. Aktivitas kegiatan pemasaran oleh UKM saat ini merupakan peran yang muncul dari jaringan dan teknologi informasi dan komunikasi (Bocconcelli et al., 2018). Sehingga teknik pemasaran dengan pemanfaatan media sosial sebagai produk dari teknologi informasi dan komunikasi merupakan pilihan yang tepat di era teknologi seperti sekarang. Kegiatan pengabdian yang dilakukan oleh Werdani et al. (2020) menyatakan bahwa strategi pemasaran melalui pemanfaatan media sosial dapat menjadi kekuatan utama untuk mendongkrak penjualan usaha. Hal ini disebabkan oleh kekuatan media sosial yang dapat memperluas jangkauan pemasaran. Selain itu, dalam kegiatan pemasaran terlebih melalui media sosial, kreatifitas pelaku UKM menjadi bagian penting yang tidak dapat dipisahkan dari kegiatan pemasaran (Widjajanti, 2015).

\section{METODE}

Peserta yang menjadi mitra dalam program pengabdian ini adalah 20 orang anggota Primer Koperasi Produsen Tempe 
Fitrah Sari Islami, Rian Destiningsih, Andhatu Achsa

Pelatihan Diversifikasi Produk nntuk Peningkatan Produktivitas Pelaku UKM Tahu

Tahu Indonesia (PRIMKOPTI) yang merupakan para pelaku UKM Tahu di Kampung Trunan Kota Magelang. Untuk mencapai tujuan dari program ini, maka metode yang digunakan adalah metode ceramah, praktik/tutorial dan kegiatan diskusi.

Untuk metode pertama yaitu ceramah, mitra diberikan pengetahuan dan pemahaman mengenai diversifikasi dan inovasi produk olahan tahu agar variasi produk ukm tahu semakin berkembang. Untuk metode kedua yaitu praktik kegiatan berupa tutorial, mitra diberikan praktik/tutorial langsung cara pembuatan salah satu varian produk yaitu tahu walik. Hal ini memberian gambaran pada para pelaku UKM Tahu mengenai produk yang dapat dihasilkan dari tahu, selain produk yang biasanya diproduksi. Metode ketiga yaitu kegiatan diskusi, mitra diberikan kesempatan untuk mendiskusikan berbagai hal terkait permasalahan UKM tahu sekaligus memberikan arahan dan ide-ide mengenai cara pemasaran produk yang berkembang saat ini untuk dapat diterapkan di UKM tahu tersebut.

\section{HASIL DAN PEMBAHASAN}

Kegiatan ini dilaksanakan di Gedung Primer Koperasi Produsen Tempe Tahu Indonesia (PRIMKOPTI) di Jalan Beringin VI No. 1, Kelurahan Tidar Selatan, Kecamatan Magelang Selatan, Kota Magelang. Kegiatan ini melibatkan para peserta yang berasal dari UKM Tahu yang juga merupakan anggota dari PRIMKOPTI tersebut.

Kegiatan dibagi atas tiga bagian yaitu : 1) kegiatan ceramah yang berisi informasi dan edukasi mengenai diversifikasi dan inovasi produk, 2) kegiatan praktik/tutorial yang berisi praktik pembuatan salah satu contoh diversifikasi produk yaitu tahu walik, dan 3) kegiatan diskusi yang berisi saling sharing dan tanya jawab untuk menggali permasalahan serta solusi dan juga memberikan ide-ide praktis mengenai cara pemasaran produk yang efektif dan efisien sesuai dengan perkembangan teknik pemasaran saat ini.

Untuk kegiatan pertama, ceramah dimulai dengan memperkenalkan apa itu diversifikasi dan inovasi. Selain itu, pemateri juga memberikan pengetahuan dan pemahaman mengenai pentingnya diversifikasi dan inovasi untuk menghadapi persaingan usaha di zaman ini. Kemudian juga dilakukan diskusi mengenai isu yang berkaitan dengan diversifikasi dan inovasi. Hasil dari kegiatan ini menunjukkan bahwa peserta selama ini tidak menganggap bahwa diversifikasi dan inovasi itu adalah suatu hal yang penting. Selain itu juga para peserta cendrung monoton dalam mengelola UKM tahu. Peserta merasa bahwa penurunan omset dan keuntungan terjadi karena sedikitnya permintaan pasar dan menurunnya minat masyarakat terhadap konsumsi tahu. Hal ini merupakan sebab dari ketidaktahuan pelaku UKM tahu mengenai manfaat diversifikasi produk.

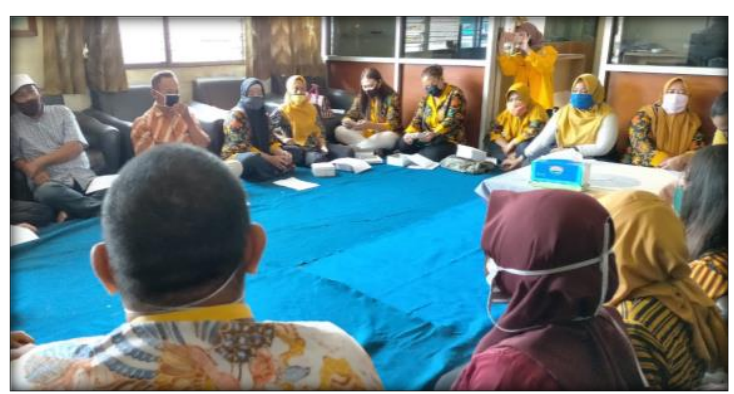

Gambar 1. Kegiatan Ceramah Mengenai

Diversifikasi dan Inovasi Produk

Selanjutnya kegiatan diskusi diarahkan pada fakta nyata di pasar saat ini, bahwa banyak produk makanan yang berhasil menarik minat masyarakat karena variasi dan inovasi yang diberikan terhadap produk tersebut. Dari kegiatan ini, maka peserta mendapatkan pengetahuan mengenai diversifikasi dan inovasi sebagai bekal untuk menambah varian produk usaha. Hal ini sejalan dengan hasil pengabdian Marka et al., (2019) dimana inovasi produk telah memberikan tambahan pengetahuan dan keterampilan bagi pelaku usaha. Sehingga tepat jika diversifikasi dan inovasi dijadikan cara untuk meningkatkan produktivitas usaha. Selain itu juga, peserta semakin tertarik untuk mengetahui lebih dalam bentuk diversifikasi produk dan inovasi produk yang bisa dibuat dengan bahan dasar tahu.

Kegiatan kedua yaitu kegiatan praktik/tutorial yang berisi praktik pembuatan salah satu contoh diversifikasi produk yaitu tahu walik. Pada kegiatan ini, pemateri memperkenalkan ragam produk berbahan 
dasar tahu seperti tahu susu, tahu bulat, tahu walik, nugget tahu, tahu bakso, tahu kulit dan lainnya.

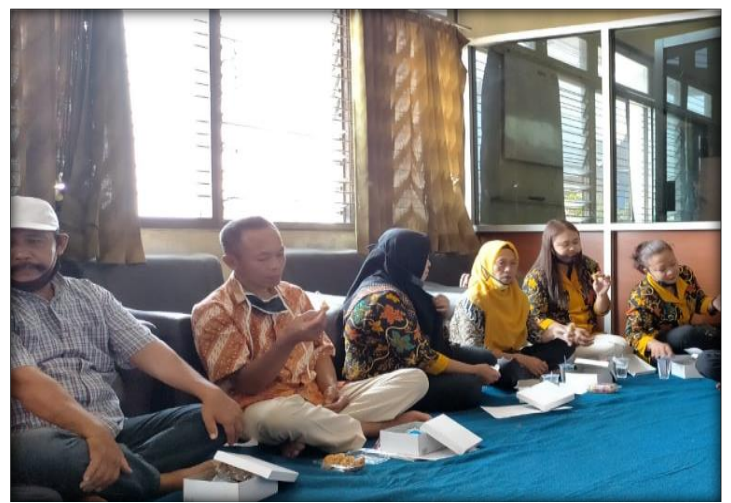

Gambar 2. Perkenalan Bentuk Diversifikasi Produk Berbahan Dasar Tahu

Semua produk ini merupakan peningkatan varian produk berbahan dasar tahu. Selanjutnya kegiatan praktik diarahkan pada pembuatan tahu walik dengan memberikan tutorial langsung pembuatan tahu walik. Praktik langsung dilakukan dengan menyajikan bahan utama yaitu tahu. Kemudian bahan tambahan lainnya yang membuat produk ini memiliki keunikan dan nikmat untuk dikonsumsi masyarakat. Para peserta juga diberikan kesempatan untuk ikut dalam pembuatan tahu walik dan juga diperkenankan untuk bertanya seputar pembuatan tahu walik.

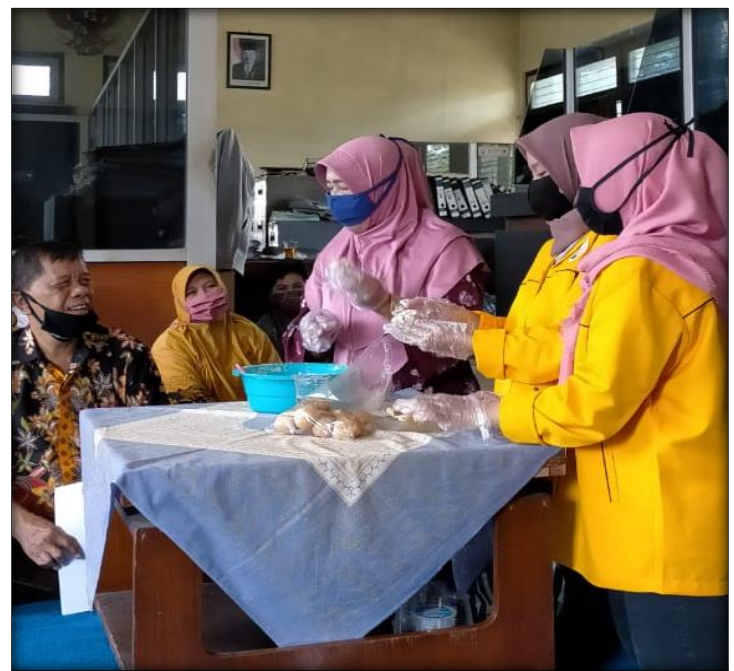

Gambar 3. Praktik/Tutorial Pembuatan Diversifikasi Produk
Selain itu, dalam kegiatan ini juga diperkenalkan bagaimana prospek bisnis tahu walik oleh pengusaha tahu walik secara langsung. Dengan modal yang cukup minim, dapat menghasilkan keuntungan yang maksimal. Sehingga para peserta semakin tertarik untuk menggali potensi diversifikasi produk dalam meningkatkan pendapatan usaha. Hal ini sejalan dengan kegiatan pengabdian yang dilakukan oleh Elita et al., (2018) dan Khairani \& Pratiwi (2018) dimana diversifikasi produk merupakan jalan dalam peningkatan omset penjualan. Hasil lainnya dari kegiatan ini yaitu para peserta mendapatkan bekal pengetahuan baru mengenai cara pembuatan varian baru produk tahu walik. Selain itu, kegiatan ini juga menambah minat para peserta untuk membuat dan menjual produk tahu walik tersebut dikarenakan adanya keuntungan yang cukup menjanjikan.

Kegiatan ketiga yaitu kegiatan diskusi yang membicarakan hal terkait permasalahan di UKM tahu dan teknik pemasaran yang sesuai untuk usaha mereka. Pada kegiatan ini, para peserta kegiatan mengungkapkan berbagai kendala terkait teknik pengemasan yang sesuai agar produk dapat menjangkau pasar modern dan pusat perbelanjaan modern seperti mall dan supermarket. Selain itu, peserta mengungkapkan kendala terkait trik pemasaran yang mungkin dapat dilakukan di zaman sekaran ini.

Kemudian pemateri memberikan pemahaman mengenai berbagai teknik pengemasan seperti pembuatan label, izin produk dan teknik kemas agar produk awet. Selain itu juga dijelaskan berbagai cara menjangkau pasar modern agar produk dapat bersaing dengan produk-produk makanan modern lainnya. Kemudian dalam menjangkau penjualan yang lebih banyak juga diberikan pemahaman terkait cara membuat promosi, penyajian foto produk yang menarik dan cara pemasaran melalui media sosial. Hasil dari kegiatan ini memberikan informasi kepada para peserta terkait solusi untuk masalah yang dihadapi serta teknik pemasaran yang tepat untuk memasarkan produk tahu guna menambah pendapatan usaha. Hal ini sejalan dengan penelitian (Werdani et al., 2020) 
dimana kegiatan pemasaran memang berfungsi untuk mendongkrak penjualan usaha.

Dari rangkaian kegiatan diatas, pertanyaan interaktif diajukan untuk mengetahui pemahaman serta kemampuan para peserta mengenai diversifikasi, inovasi dan pemasaran produk. Dari kegiatan tersebut para peserta sudah sangat memahami pentingnya diversifikasi dan inovasi serta triktrik pemasaran yang tepat untuk kegiatan usaha mereka. Sehingga membuka pikiran para peserta untuk mengimplementasikan rangkaian kegiatan tersebut dalam usaha mereka. Berdasarkan rangkaian kegiatan yang telah dilakukan, maka representasi pemahaman peserta disajikan dalam grafik di bawah ini.

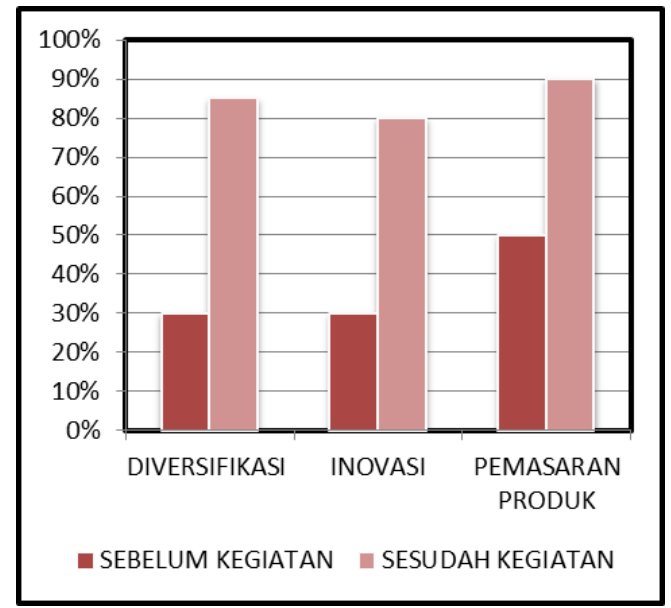

Gambar 4. Peningkatan Pemahaman Peserta

Peningkatan pemahaman tersebut diharapkan dapat menjadi modal untuk meningkatkan produktivitas para pelaku UKM tahu sehingga dapat meningkatkan kesejahteraan semua pelaku UKM tahu di Kampung Trunan. Diharapkan juga dengan adanya kegiatan praktik/tutorial, dapat memberikan ilmu langsung untuk diaplikasikan kedalam variasi produk usaha UKM tahu.

\section{SIMPULAN}

Kegiatan pengabdian yang diikuti oleh para pelaku UKM tahu di Kampung Trunan, Kota Magelang memberikan pengalaman mengenai pengetahuan lebih dalam bentuk diversifikasi produk yang bisa dibuat dengan bahan dasar tahu. Peserta juga mendapatkan bekal pengetahuan baru mengenai cara pembuatan varian produk yaitu tahu walik dan menambah minat para peserta untuk membuat dan menjual produk tahu walik. Selain itu, peserta mendapatkan informasi terkait solusi untuk masalah yang dihadapi UKM tahu serta teknik pemasaran yang tepat untuk memasarkan produk tahu tersebut. Rangkaian kegiatan menjadi solusi atas permasalahan para pelaku UKM tahu sehingga diharapkan dapat meningkatkan kesejahteraan pelaku UKM tahu melalui peningkatan produktivitas serta peningkatan penjualan.

\section{DAFTAR PUSTAKA}

Anggraini, R., Maulina, F., \& Vivi, V. (2019). Pemberdayaan masyarakat melalui diversifikasi produk keladi dan singkong. JPPM (Jurnal Pengabdian Dan Pemberdayaan Masyarakat), 3(1), 63. https://doi.org/10.30595/jppm.v3i1.3028

Bocconcelli, R., Cioppi, M., Fortezza, F., Francioni, B., Pagano, A., Savelli, E., \& Splendiani, S. (2018). SMEs and Marketing: A Systematic Literature Review. International Journal of Management Reviews, 20(2), 227-254. https://doi.org/10.1111/ijmr.12128

Brines, S., Shepherd, D., \& Woods, C. (2013). SME family business innovation: exploring new combinations. Journal of Family Business Management, 3(2), 117135. https://doi.org/10.1108/JFBM-012012-0002

Elita, N., Darnetti, D., \& Harmailis, H. (2018). Peningkatan usaha melalui diversifikasi produk kerajinan tenun kubang Kabupaten Lima Puluh Kota. Dinamisia : Jurnal Pengabdian Kepada Masyarakat, 2(2), 335-340. https://doi.org/10.31849/dinamisia.v2i2.1 685

Haddad, M. I., Williams, I. A., Hammoud, M. S., \& Dwyer, R. J. (2019). Strategies for implementing innovation in small and medium-sized enterprises. World Journal of Entrepreneurship, Management and Sustainable Development, 16(1), 12-29. https://doi.org/10.1108/WJEMSD-05- 
2019-0032

Khairani, S., \& Pratiwi, R. (2018). Peningkatan omset penjualan melalui diversifikasi produk dan dtrategi promosi pada UMKM kerajinan souvenir khas palembang. CARADDE: Jurnal Pengabdian Kepada Masyarakat, 1(1), 36-43.

https://doi.org/10.31960/caradde.v1i1.18

Marka, M. M., Azis, N., \& Alifiana, M. A. (2019). Pengembangan UMKM Madumongso melalui manajemen usaha dan legalitas usaha. Jurnal Abdimas, 22(2), 185-192. Retrieved from https://www.emerald.com/insight/content /doi/10.1108/JFBM-01-2012-

0002/full/html

Murphy, G., \& Tocher, N. (2017). Diversification in small firms: Does parental influence matter? Journal of Small Business Strategy, 27(3), 25-38.

Saunila, M. (2019). Innovation capability in SMEs: A systematic review of the literature. Journal of Innovation \& Knowledge, 4(1), 59-67. https://doi.org/10.1016/j.jik.2019.11.002

Werdani, R. E., Kurniawati, N. I., Sukoco, J. B., Windriya, A., \& Iskandar, D. (2020). Pelatihan pemasaran produk homemade melalui sosial media. JPPM (Jurnal Pengabdian Dan Pemberdayaan Masyarakat), 4(1), 1. https://doi.org/10.30595/jppm.v4i1.4655

Widjajanti, K. (2015). Marketing collaboration and SME strategy implementation in Blora, Indonesia. ASEAN Marketing Journal, $\quad 7(1), \quad 28-39$. https://doi.org/10.21002/amj.v7i1.4482 